\title{
Prevalência de má oclusão em crianças de 7 a 12 anos de idade
}

\author{
Marcio Rodrigues de Almeida*, Alex Luiz Pozzobon Pereira**, Renato Rodrigues de Almeida***,

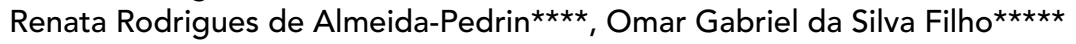

\section{Resumo}

Objetivo: verificar a prevalência de más oclusões em 3.466 crianças com 7 a 12 anos de idade, matriculadas em escolas públicas nas cidades de Lins/SP e Promissão/SP. Métodos: considerou-se a relação sagital entre as arcadas dentárias, a relação interarcadas no sentido transversal e a relação de incisivos nos sentidos vertical e horizontal. Na relação intra-arcada avaliou-se a prevalência de diastemas, apinhamentos e perdas dentárias. Resultados: entre as más oclusões, $55,25 \%$ das crianças apresentaram uma relação molar de Classe I, seguida de 38\% de Classe II e 6,75\% de Classe III. Na relação de incisivos houve prevalência de mordida aberta em 17,65\% dos casos, seguida de 13,28\% para mordida profunda e 5,05\% de mordida cruzada anterior. A mordida cruzada posterior foi encontrada em 13,3\% das crianças. Na relação intra-arcada, $31,88 \%$ das crianças mostraram diastemas; $31,59 \%$, apinhamento; e 4,65\%, perdas dentárias.

Palavras-chave: Má oclusão. Classificação de Angle. Oclusão normal. Epidemiologia.

\section{INTRODUÇÃO E REVISÃO DE LITERATURA}

O estudo de uma oclusão "normal", assim como as características mais frequentes que compõem esse quadro, deve ser imperioso para o ortodontista ${ }^{1}$. Não é difícil identificar uma oclusão normal. Pelo menos três requisitos básicos deverão estar presentes: 1) a inclusão total da arcada dentária inferior dentro da arcada dentária superior; 2) a relação sagital correta entre os dentes do segmento posterior, ou seja, uma relação de Classe I; e 3) relação de incisivos com trespasses horizontal e

Como citar este artigo: Almeida MR, Pereira ALP, Almeida RR, Almeida-Pedrin RR, Silva Filho OG. Prevalência de má oclusão em crianças de 7 a 12 anos de idade. Dental Press J Orthod. 2011 July-Aug;16(4):123-31. vertical positivos. De fato, a aspiração por definir essas características é secular. Edward Hartley Angle $^{6}$, no final do século XIX, foi o primeiro a considerar a relação sagital entre as arcadas dentárias, usando como referência a relação de molares, e deu o nome de "Classe" para a relação que esses dentes poderiam apresentar. A relação sagital correta entre os molares recebeu a designação de Classe I e exigia que a cúspide mesiovestibular do primeiro molar permanente superior repousasse no sulco vestibular do primeiro molar permanente inferior.

* Mestrado, Doutorado e Pós-Doutorado em Ortodontia pela Faculdade de Odontologia de Bauru, Universidade de São Paulo. Professor Adjunto Doutor do Curso de Mestrado em Ortodontia da Universidade Norte do Paraná (UNOPAR), Campus Londrina.

** Mestrado e Doutorado pela Faculdade de Odontologia de Araçatuba, UNESP. Professor de Ortodontia da Faculdade de São Luís do Maranhão.

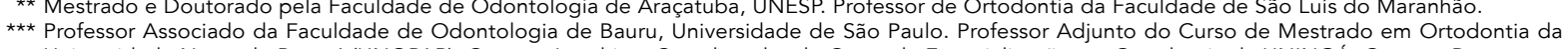
Universidade Norte do Paraná (UNOPAR), Campus Londrina. Coordenador do Curso de Especialização em Ortodontia da UNINGÁ, Campus Bauru.

**** Mestrado, Doutorado e Pós-Doutorado em Ortodontia pela Faculdade de Odontologia de Bauru, Universidade de São Paulo. Professora do Curso de Especialização em Ortodontia da UNINGÁ, Campus Bauru.

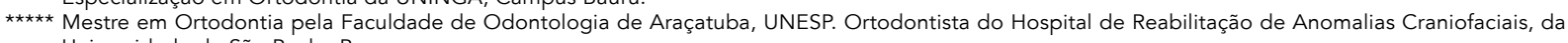
Universidade de São Paulo, Bauru. 
Angle $^{6}$ também identificou mais duas Classes para definir o comportamento sagital entre os molares: Classe II e Classe III. Então, considerou que, na Classe II, a arcada dentária inferior se encontra em relação distal com a arcada dentária superior; enquanto na Classe III, o primeiro molar permanente inferior encontra-se em posição mesial na relação com o primeiro molar permanente superior.

Não há polêmica em afirmar que, entre as populações, a má oclusão prevalece em relação à oclusão normal, independentemente do estágio do desenvolvimento da oclusão $2,4,7,8,9,11,14-17,20,21,22$. O predomínio de má oclusão justifica-se pela etiologia multifatorial $4,5,10,13,19$, incluindo os fatores genéticos ${ }^{23}$ e inúmeros fatores ambientais, $3,6,16,18,23,24$ — que, somados, contribuem para o surgimento dos diferentes tipos de má oclusão. Os estudos epidemiológicos têm demonstrado que a má oclusão Classe I predomina, com manifestação de desordens oclusais nos sentidos transversal e vertical; seguida pela má oclusão Classe II e, em menor frequência, pela Classe III ${ }^{2,7,8,9,11,14-17,20,21,22}$.

Portanto, alicerçado nas informações da literatura consultada, procurou-se determinar a prevalência das más oclusões nos três planos do espaço, bem como a presença de apinhamentos, diastemas e perdas dentárias em crianças na faixa etária compreendida entre 7 e 12 anos, matriculadas em escolas públicas das cidades de Lins/SP e Promissão/SP.

\section{MATERIAL E MÉTODOS}

Foram avaliados 3.466 escolares de ambos os sexos na faixa etária de 7 a 12 anos, matriculados nas escolas públicas das cidades de Lins/SP e Promissão/SP. Não houve preocupação na identificação de sexo ou raça e, tampouco, na identificação dos estágios do desenvolvimento oclusal — dentições decídua, mista ou permanente - , visto que nessa faixa etária a dentição mista prevalece. Também não foi objeto de estudo identificar a incidência de hábitos bucais deletérios.

O exame bucal foi realizado por alunos do $7^{\circ}$ e $8^{\circ}$ semestres do Curso de Odontologia e alunos do Curso de Especialização em Ortodontia da Fa- culdade de Odontologia de Lins (FOL/UNIMEP), devidamente paramentados (uniforme, luvas, touca, óculos), sob a orientação de um dos professores da disciplina de Ortodontia.

Utilizou-se espátulas descartáveis, réguas, lapiseiras, canetas e o questionário exibido na Figura 1 , onde foram registrados os exames e os dados de identificação dos escolares, mediante o acompanhamento teórico-prático aos mesmos para que o levantamento tivesse o êxito esperado.

Para o exame clínico, as crianças foram sentadas comodamente e direcionadas para uma fonte abundante de luz. Todos os exames foram iniciados pedindo-se às crianças para que abrissem a boca, permitindo-se, assim, que se registrassem os dados previamente escolhidos. Posteriormente, solicitou-se que as crianças ocluíssem em posição habitual (máxima intercuspidação) para que se colhetassem dados mais específicos. Algumas crianças tiveram dificuldade para ocluir em posição habitual e, nesses casos, pediu-se que posicionassem a ponta da língua o mais posteriormente possível no palato e ocluíssem comodamente.

A análise dos dados oclusais respeitou os preceitos de Angle ${ }^{6}$, que dividiu e agrupou as más oclusões em: (A) Classe I — englobando os casos de má oclusão onde a relação anteroposterior dos primeiros molares superior e inferior está normal. Isso significa que a mandíbula e a arcada dentária a ela superposta estão em correta relação mesiodistal com a maxila e demais ossos da face. A cúspide mesiovestibular do primeiro molar superior oclui no sulco central do primeiro molar inferior. A má oclusão está geralmente confinada aos dentes anteriores. (B) Classe II - casos onde a arcada inferior se encontra em relação distal com a arcada superior. A cúspide mesiovestibular do primeiro molar superior oclui no espaço entre a cúspide vestibular do primeiro molar inferior e a face distal da cúspide vestibular do segundo pré-molar inferior. Apresenta duas divisões: (b.1) Classe II, $1^{\text {a }}$ divisão - a característica marcante é a protrusão dos incisivos superiores, que apresentam uma inclinação axial vestibular. 
A forma da arcada se assemelha a um "V", estando geralmente associada com funções musculares anormais, respiração bucal ou hábitos de sucção de dedo, língua ou chupeta. (b.2) Classe II, $2^{\mathrm{a}}$ divisão — sua principal característica é a inclinação axial vertical ou lingual dos incisivos superiores. A arcada superior geralmente apresenta-se achatada na região anterior, devido à inclinação lingual excessiva dos incisivos centrais superiores. Existe uma sobremordida profunda, e a arcada inferior frequentemente apresenta curva de Spee exagerada. A função muscular e a respiração são normais. (b.3) Subdivisão quando os molares de um lado apresentam relações de Classe I e os do lado oposto, relação de Classe II. Recebe a denominação de subdivisão direita ou esquerda, conforme a chave de oclusão de Classe II esteja do lado direito ou esquerdo, respectivamente. (C) Classe III — são aqueles casos em que o primeiro molar inferior encontra-se em posição mesial na relação com o primeiro molar superior. A cúspide mesiovestibular do primeiro molar superior oclui no espaço entre a cúspide distal do primeiro molar inferior e a cúspide mesiovestibular do segundo molar inferior. Também nesse caso, emprega-se a subdivisão quando um dos lados permanece em chave de oclusão. Os incisivos podem ou não apresentar mordida cruzada, com as faces vestibulares dos incisivos superiores contatando com as faces linguais dos incisivos inferiores. Os incisivos e caninos inferiores encontram-se com excessiva inclinação lingual. Frequentemente a arcada superior está atrésica.

Como critério para a classificação da mordida profunda, utilizou-se um trespasse vertical positivo acima de $4 \mathrm{~mm}$; e para a mordida aberta anterior, um trepasse vertical negativo de no mínimo $1 \mathrm{~mm}$, de acordo com Silva Filho et al. ${ }^{17}$

Anteriormente ao início da pesquisa, procurou-se efetuar contato com as diretorias das escolas e com os professores, no intuito de esclarecer o objetivo do estudo: levantamento epidemiológico para caracterização das más oclusões. A colaboração constatada foi de $100 \%$ dos pesquisados. Além disso, utilizou-se um questionário de termo

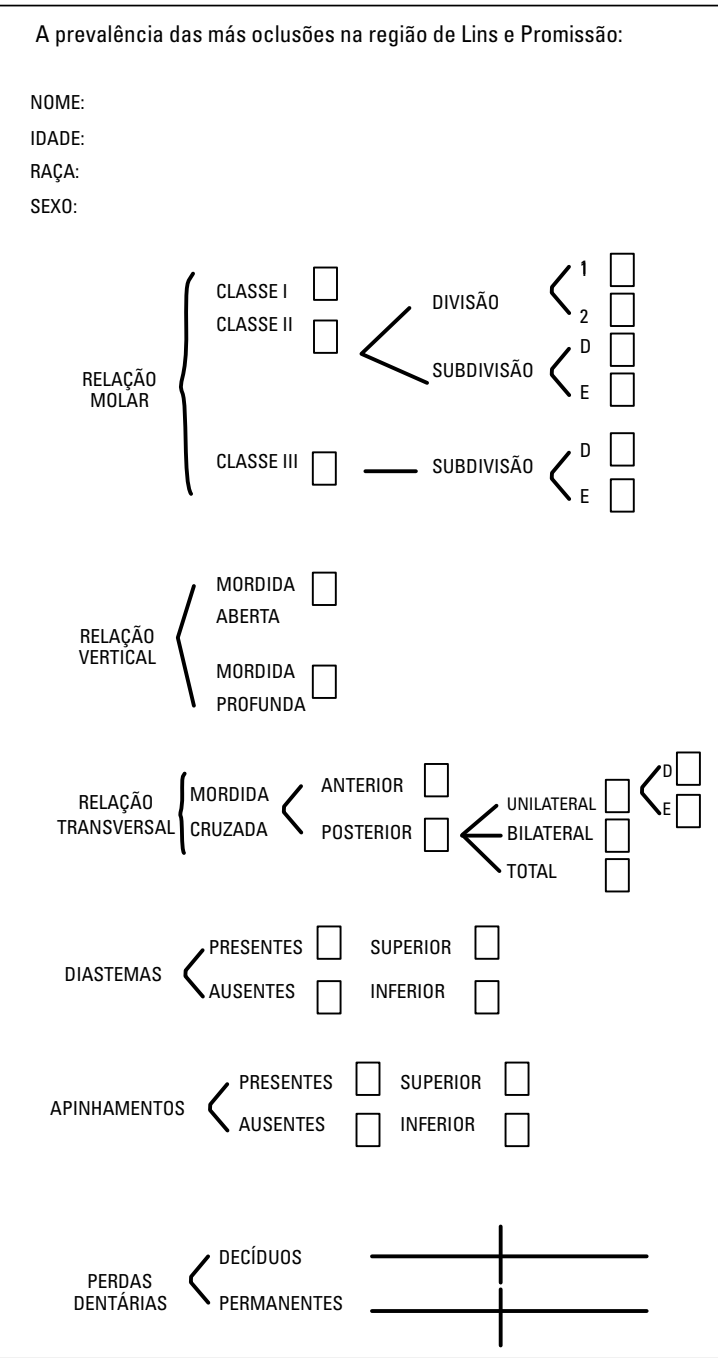

FIGURA 1 - Questionário utilizado no estudo.

de consentimento livre e esclarecido para os pais das crianças participantes.

\section{RESULTADOS E DISCUSSÃO}

O objetivo do presente estudo foi realizar um levantamento epidemiológico que possibilitasse caracterizar as más oclusões em escolares de primeiro grau - nas cidades de Lins e Promissão, estado de São Paulo - , tendo como premissa que a má oclusão está presente em percentagem considerável em todas as comunidades, independentemente da etnia, raça, gênero e idade $2,7,8,9,11,14-17,20,21,22$. De fato, a má oclusão é considerada, pela Organização Mundial da saúde, o 
terceiro maior problema de saúde pública, visto que os levantamentos epidemiológicos realizados em cidades brasileiras e em outros países apontaram uma incidência relevante de má oclusão. Essa realidade se faz presente desde a dentição decídua ${ }^{7,8,9,11,14,15,20,21,22}$.

Na cidade de Bauru/SP, foram realizados, por meio de ortodontistas, dois levantamentos epidemiológicos avaliando crianças ${ }^{15,17}$. No primeiro levantamento, publicado em 1990, abrangendo 2.416 crianças no estágio de dentição mista, a má oclusão esteve presente em $88,53 \%$ da amostra ${ }^{17}$. O segundo levantamento epidemiológico, mais recente, veio complementar o primeiro, definindo a caracterização da oclusão na dentição decídua. A incidência de má oclusão encontrada para a dentição decídua foi próxima de $73 \%$ da amostra ${ }^{15}$. Portanto, a prevalência de má oclusão encontrada na dentição mista foi mais alta do que a encontrada em crianças na dentição decídua - respectivamente, $73 \%$ e $88 \%$. Essa comparação transversal denota o aparecimento precoce dos desvios morfológicos a partir da dentição decídua e a ausência de autocorreção das más oclusões instaladas, pelo menos desde a dentição decídua até a dentição mista.

Quando esses dados são comparados com os obtidos em levantamento prévio, realizado na década de 1970, também na população de Bauru, porém na dentição permanente (perto de 90\% de má oclusão), mantém-se a afirmação de que a má oclusão não se autocorrige da dentição decídua para a mista e, tampouco, da dentição mista para a permanente. Alicerçado nos dados epidemiológicos transversais, conclui-se que a má oclusão mantém-se com predominância nos três estágios do desenvolvimento da oclusão, sem alteração epidemiológica com o passar do tempo. Pode-se resumir assim a prevalência de má oclusão nas crianças da cidade de Bauru/SP: 73\%, 88\% e 90\%, respectivamente, nas dentições decídua, mista e permanente (Gráf. 1). Esses dados querem dizer apenas que a maior parte das populações avaliadas apresenta algum desvio da normalidade oclusal. Não se avaliou a gravidade da má oclusão, o que definiria a real necessidade de tratamento ortodôntico. Esse é um dos motivos que justificam a alta incidência de má oclusão, já que todos os desvios morfológicos, independentemente da sua magnitude, foram catalogados como má oclusão. O segundo motivo para a incidência elevada de má oclusão deve-se à metodologia minuciosa levada a cabo por profissionais com formação em Ortodontia.

A distribuição geral das más oclusões encontradas nas cidades de Lins e Promissão, por ordem decrescente de incidência, foi a seguinte: Classe I $(55,25 \%)$, seguida pela Classe II (38\%) e, finalmente, Classe III (6,75\%) (Tab. 1, Gráf. 2).

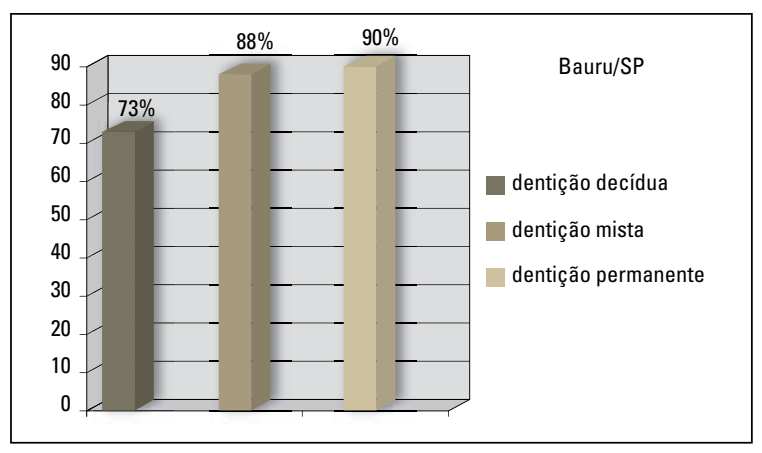

GRÁFICO 1 - Porcentagem das más oclusões encontradas nos diferentes estágios do desenvolvimento oclusal (dentições decídua, mista e permanente) na cidade de Bauru/SP (Silva Filho et al. ${ }^{15,17}$ ).

TABELA 1 - Relação molar nas más oclusões.

\begin{tabular}{ccc} 
Relação molar & $\mathbf{n}$ & $\%$ \\
\hline Classe I & 1.915 & 55,25 \\
Classe II & 1.317 & 38 \\
Classe III & 234 & 6,75 \\
Total & 3.466 & 100 \\
\hline
\end{tabular}

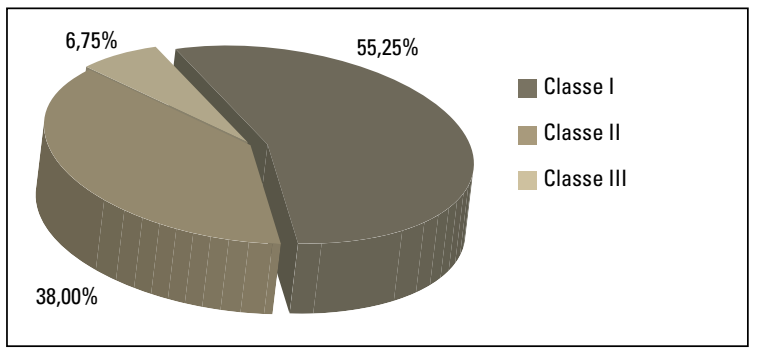

GRÁFICO 2 - Relação molar nas más oclusões. 
Em relação aos dados encontrados na literatura, a distribuição das más oclusões de acordo com a relação sagital entre as arcadas dentárias é muito similar. Nos levantamentos feitos na cidade de Bau$\mathrm{ru} / \mathrm{SP}$ em $1990^{17}$ e em $2002^{15}$, os resultados para a dentição decídua foram: 50\% Classe I, 45,9\% Classe II e 4\% Classe III. Para a dentição mista, a distribuição das más oclusões foi semelhante, com $55 \%$ para a Classe I, 42\% para a Classe II e 3\% para a Classe III (Tab. 2). Embora o universo dessa pesquisa tenha sido maior, comparado ao dos levantamentos descritos anteriormente, esses resultados são muito semelhantes. A variação maior foi para a incidência das más oclusões de Classe II e Classe III, na população de Lins e Promissão. Há que se fazer uma ressalva metodológica. No levantamento feito em Lins e Promissão, a relação sagital foi definida pela relação molar, enquanto nos dois levantamentos de Bauru, a definição sagital usou a chave de canino decíduo ou pré-molar, na dependência da presença do pré-molar na oclusão. Além disso, sabe-se que na região de Lins/SP existe uma maior miscigenação racial de xantodermas, o que pode explicar a maior variação para a má oclusão de Classe III.

Encontrou-se mordida aberta em 17,65\% das crianças avaliadas nas cidades de Lins e Promissão (Gráf. 3). Normalmente, a mordida aberta anterior está relacionada a hábitos bucais de sucção e pressionamento lingual atípico ${ }^{3,4,18,24}$ e, como os hábitos de sucção estão mais presentes na infância, sua incidência tende a ser maior nesse estágio. Na dentição decídua a incidência de mordida aberta anterior encontrada nas crianças de Bauru foi de $27,97 \%$ da amostra $^{15}$.

TABELA 2 - Distribuição da relação molar nos levantamentos epidemiológicos realizados em Bauru (Silva Filho et al. ${ }^{15,17}$ ), na dentição decídua e na dentição mista, e no levantamento epidemiológico em Lins e Promissão.

\begin{tabular}{cccc} 
Relação molar & $\begin{array}{c}\text { Dentição } \\
\text { decídua em } \\
\text { Bauru }\end{array}$ & $\begin{array}{c}\text { Dentição } \\
\text { mista em } \\
\text { Bauru }\end{array}$ & $\begin{array}{c}\text { 6-12 anos } \\
\text { Lins e } \\
\text { Promissão }\end{array}$ \\
\hline Classe I & $50,0 \%$ & $55,0 \%$ & $55,25 \%$ \\
Classe II & $46,0 \%$ & $42,0 \%$ & $38,00 \%$ \\
Classe III & $4,0 \%$ & $3,0 \%$ & $6,75 \%$ \\
\hline
\end{tabular}

Essa incidência reduziu-se para 23\% na dentição mista ${ }^{17}$; portanto, próximo da prevalência de mordida aberta anterior encontrada nas crianças de Lins e Promissão. Como o levantamento realizado na dentição mista excluiu a dentição permanente completa, as crianças tinham menos idade cronológica do que as crianças recém avaliadas em Lins e Promissão. Isso provavelmente deve ter influenciado a estatística. Assim, podemos quantificar a incidência de mordida aberta anterior em Bauru, Lins e Promissão: $28 \%$ na dentição decídua; $23 \%$ na dentição mista em Bauru; e cerca de 17\% na população de Lins e Promissão, que abrange uma faixa etária dos 7 aos 12 anos de idade. Esses dados refletem o comportamento espontâneo dos hábitos de sucção na vida infantil, como sugerido nos Gráficos 4 e 5 - que revelam a incidência de hábitos ao longo dos anos, durante a dentição decídua. Eles tendem a se reduzir a partir da dentição decídua para a permanente ${ }^{10}$. É de bom-senso abordar terapeuticamente os hábitos no final da dentição decídua, preparando o ambiente muscular e alveolar para a erupção dos incisivos permanentes, ou seja, criando as condições morfológicas propícias para uma relação de incisivos correta durante a erupção dos incisivos permanentes.

\begin{tabular}{ccc|}
\hline TABELA 3 - Relação vertical nas mordidas. & \\
\hline Relação vertical & $\mathbf{n}$ & $\%$ \\
\hline Mordida aberta & 612 & 17,65 \\
\hline Mordida profunda & 460 & 13,28 \\
Normal & 2.394 & 69,07 \\
\hline Total & 3.466 & 100 \\
\hline
\end{tabular}

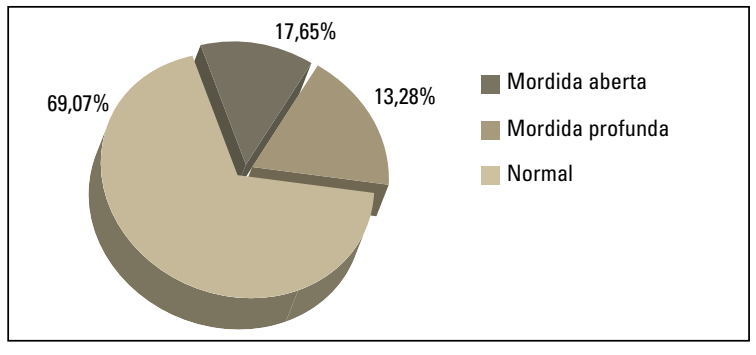

GRÁFICO 3 - Relação vertical das mordidas. 


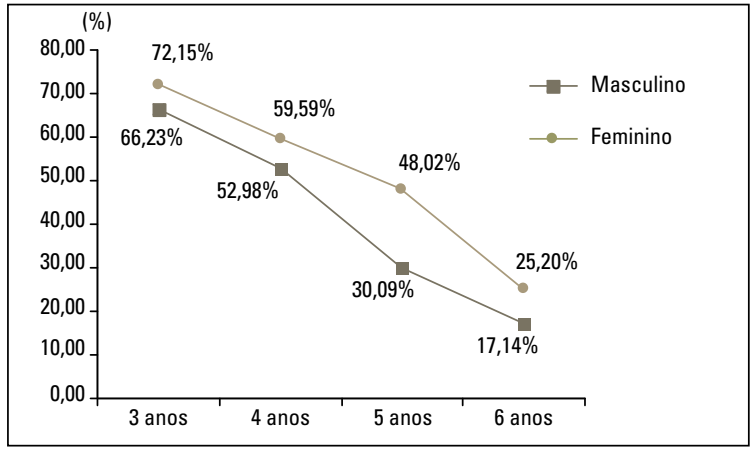

GRÁFICO 4 - Avaliação transversal da presença de hábitos bucais de sucção nas 2.016 crianças avaliadas no estágio de dentição decídua, entre 3 e 6 anos de idade, de acordo com o sexo, em porcentagem (Silva Filho et al. ${ }^{15}$.

$\mathrm{X}^{2}{ }_{\text {(sexo feminino) }}=80,94, \mathrm{p}<0,001^{*} ; \mathrm{X}^{2}{ }_{\text {(sexo masculino) }}=124,59, \mathrm{p}<0,001^{*}$

A mordida profunda ou sobremordida esteve presente em 13,28\% da amostra estudada (Gráf. 3). Quanto às relações transversal e horizontal das mordidas cruzadas, observou-se $5,05 \%$ para a anterior e $13,3 \%$ para a posterior nas cidades de Lins e Promissão (Tab. 4, Gráf. 6). Quanto à mordida cruzada anterior, a incidência, de $3,57 \%$, foi maior que a encontrada para a dentição decídua ${ }^{15}$ e menor que a registrada na dentição mista de Bauru $^{17}$, de 7,6\%. A incidência de mordida cruzada posterior identificada em Lins e Promissão ficou intermediária em relação às amostras de Bauru, nas dentições decídua e mista, que foram de $11,65 \%$ e $18,2 \%$, respectivamente.

A presença de diastemas foi encontrada em 31,88\% dos casos pesquisados (Tab. 5, Gráf. 7). O diastema pode ser definido como a ausência de contato entre dois ou mais dentes consecutivos. É considerado anormal na dentição permanente, e desagradável do ponto de vista estético, porém funcionalmente reduz pouco, ou nada, a eficiência mastigatória.

O apinhamento dentário deve-se à discrepância entre o perímetro da arcada dentária e a massa dentária, seja de caráter ambiental ou genético. $\mathrm{Na}$ dentição decídua sua prevalência é insignificante, alcançando cerca de 10\% das crianças. Porém, a partir da dentição mista,

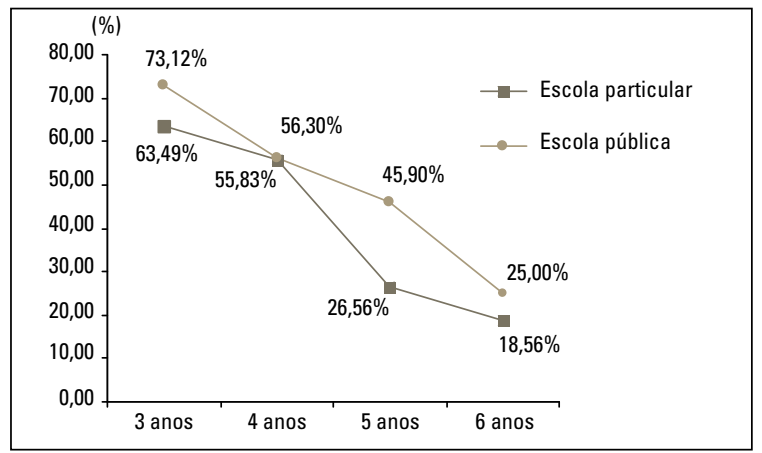

GRÁFICO 5 - Avaliação transversal da presença de hábitos bucais de sucção nas 2.016 crianças avaliadas no estágio de dentição decídua, entre 3 e 6 anos de idade, de acordo com o nível socioeconômico, em porcentagem (Silva Filho et al. ${ }^{15}$ ).

$\mathrm{X}^{2}{ }_{\text {(escola pública) }}=85,69, \mathrm{p}<0,001^{*} ; \mathrm{X}^{2}$ (escola particular) $=113,69, \mathrm{p}<0,001^{*}$

TABELA 4 - Relação horizontal e transversal das mordidas cruzadas.

\begin{tabular}{ccc} 
Mordida cruzada & $\mathbf{n}$ & $\%$ \\
\hline Anterior & 175 & 5,05 \\
\hline Posterior & 461 & 13,3 \\
Normal & 2.830 & 81,65 \\
Total & 3.466 & 100 \\
\hline
\end{tabular}

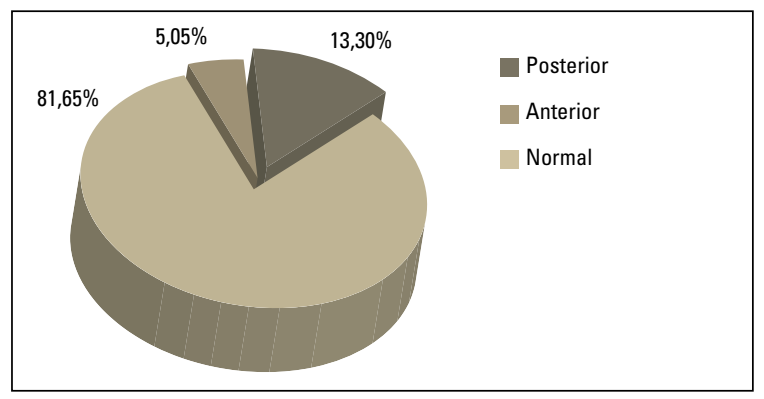

GRÁFICO 6 - Relação horizontal e transversal das mordidas cruzadas.

ganha significância epidemiológica, pois sua incidência aumenta consideravelmente, e também sob o ponto de vista terapêutico, já que o tratamento pode ser iniciado nessa fase de desenvolvimento da oclusão. A porcentagem de crianças com apinhamento foi de 31,59\% (Tab. 6, Gráf. 8). Esse dado é bem inferior ao encontrado no levantamento realizado na dentição mista em 1990, com cerca de 50\% da amostra ${ }^{17}$. Em parte, pelo menos, isso pode ser explicado pelo fato de 
TABELA 5 - Presença de diastemas.

\begin{tabular}{ccc} 
Diastemas & $\mathbf{n}$ & $\%$ \\
\hline Presentes & 1.105 & 31,88 \\
\hline Ausentes & 2.361 & 68,12 \\
\hline Total & 3.466 & 100 \\
\hline
\end{tabular}

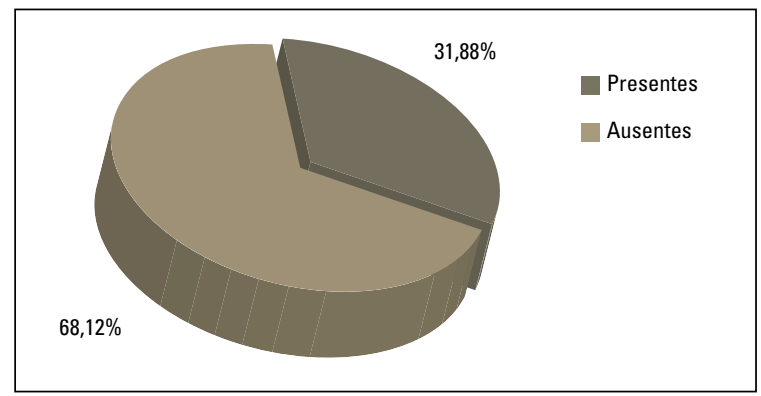

GRÁFICO 7 - Presença de diastemas.

algum apinhamento ter sido dissolvido espontaneamente nas crianças de Lins e Promissão, visto que algumas delas encontravam-se no estágio de dentição permanente. É sabido que o apinhamento na dentição mista, conhecido como apinhamento primário temporário, tem correção espontânea durante a dentição mista ${ }^{10}$.

As perdas dentárias estiveram presentes em 4,65\% dos 3.466 escolares pesquisados nas cidades de Lins e Promissão (Tab. 7, Gráf. 9). As perdas dentárias precoces estão associadas principalmente à cárie e aos hábitos de saúde bucal e constituem-se, também, num problema de saúde pública $^{12}$ que vem sendo combatido por meio da prevenção e da oferta de profissionais da área da Odontologia na rede estadual de ensino e na rede básica de saúde, assim como pela atuação das escolas de Odontologia que realizam trabalho preventivo na área de Odontologia social em suas regiões de abrangência. Os dados obtidos nas cidades de Lins e Promissão são animadores se levar-se em consideração que as perdas dentárias são menos frequentes que as perdas dentárias encontradas nas crianças estudadas na década passada ${ }^{17}$, permitindo inferir que o sistema de prevenção tem se mostrado eficiente.
TABELA 6 - Presença de apinhamentos.

\begin{tabular}{ccc} 
Apinhamentos & $\mathbf{n}$ & $\%$ \\
\hline Presentes & 1.095 & 31,59 \\
Ausentes & 2.371 & 68,41 \\
Total & 3.466 & 100 \\
\hline
\end{tabular}

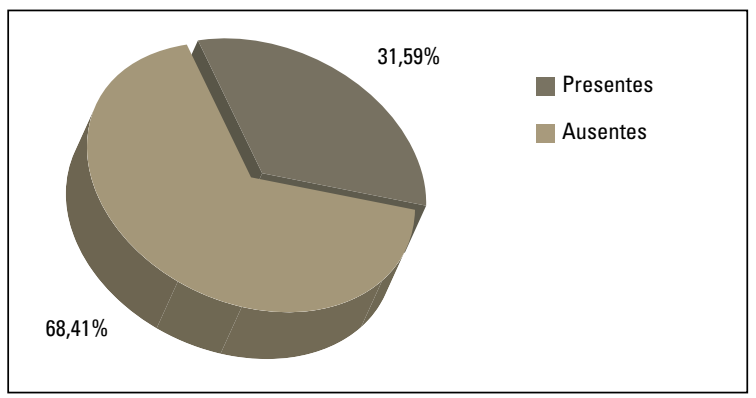

GRÁFICO 8 - Presença de apinhamentos.

TABELA 7 - Presença de perdas dentárias em relação ao total de casos.

$\begin{array}{ccc}\text { Perdas dentárias } & \mathrm{n} & \% \\ \text { Perdas dentárias } & 161 & 4,65 \\ \begin{array}{c}\text { Dentição } \\ \text { preservada }\end{array} & 3.305 & 95,35 \\ \text { Total } & 3.466 & 100\end{array}$

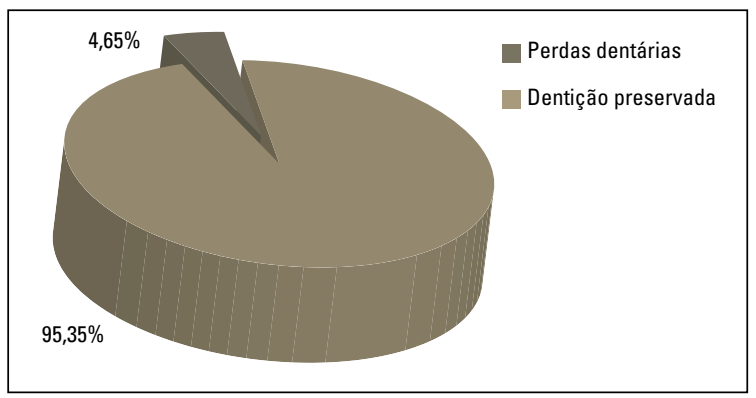

GRÁFICO 9 - Presença de perdas dentárias.

Além disso, os dados do presente estudo parecem corroborar os resultados obtidos por Almeida et al. ${ }^{2}$ com relação à diminuição da incidência de má oclusão em cidades com fluoretação de água de abastecimento público. É extremamente válido ressaltar-se que essa diminuição não está relacionada com os fatores genéticos do crescimento responsáveis pela determinação do padrão 
facial, mas diretamente relacionada com a diminuição da perda dentária e redução das áreas de contatos interdentários, provenientes de cáries interproximais extensas.

De qualquer maneira, as más oclusões apresentam uma etiologia multifatorial ${ }^{5,10,19}$ e a perda dentária e a redução dos contatos interdentários representam apenas um dos fatores etiológicos (ambientais) responsáveis pelo surgimento da má oclusão.

\section{CONCLUSÃO}

O presente levantamento epidemiológico permitiu estabelecer a caracterização morfológica da má oclusão em escolares das cidades de Lins/SP e Promissão/SP, num total de 3.466 alunos, cujas idades variaram de 7 a 12 anos. Os dados levantados permitem concluir que:

» O comportamento sagital das más oclusões faz prevalecer a Classe I, com uma prevalência de $55,25 \%$, seguida pela Classe II, em 38\% das crianças, e pela Classe III, em 6,75\%.
》Quanto ao comportamento vertical, 17,28\% das crianças exibiram mordida aberta anterior enquanto $13,28 \%$, mordida profunda.

» A mordida cruzada posterior manifestou-se em 13,3\% da amostra total.

» A mordida cruzada anterior apresentou-se em 5,05\% da amostra total.

» Os diastemas estavam presentes em 31,88\% e os apinhamentos em $31,59 \%$ das crianças.

»As perdas dentárias foram identificadas em $4,65 \%$ dos casos pesquisados.

\section{AGRADECIMENTO}

Agradecemos a colaboração dos ex-alunos Fabiana Babosa Silva, Patrícia Del Grossi e Ricardo Humberto Artioli Grassi, do Curso de Odontologia; e os ex-alunos Luiz Fábio Silva Ferrato e Paulo Roberto Miranda, do Curso de Especialização em Ortodontia da Faculdade de Odontologia de Lins (FOL/UNIMEP) pela participação na seleção da amostra.

\title{
Prevalence of malocclusion in children aged 7 to 12 years
}

\author{
Abstract \\ Objectives: This study determined the prevalence of malocclusion in a group of 3,466 children aged 7 to 12 years \\ enrolled in public school in the cities of Lins and Promissão, in the state of São Paulo, Brazil. Methods: It was ana- \\ lyzed the sagittal relationships between dental arches, the transverse relationship between arches, and the vertical \\ and horizontal relations of incisors. The prevalence of diastemas, crowding and tooth losses were evaluated. Results: \\ Among the types of malocclusion, 55.25\% of the children had a Class I molar relationship; 38\%, Class II; and 6.75\%, \\ Class III. The analysis of incisor relationships revealed $17.65 \%$ of open bite, followed by $13.28 \%$ of deep bite and \\ $5.05 \%$ of anterior crossbite; $13.3 \%$ of the children had a posterior crossbite. The analysis of relationships between \\ arches showed that $31.88 \%$ of the children had diastemas; $31.59 \%$, crowding; and 4.65 , tooth losses.
}

Keywords: Malocclusion. Angle classification. Normal occlusion. Epidemiology. 


\section{REFERÊNCIAS}

1. Ackerman JL, Proffit WR. The characteristics of malocclusion: a modern approach to classification and diagnosis. Am J Orthod. 1969:56(5):443-54.

2. Almeida RR, Feeo OS, Martins DR. Influência da fluoretação na prevalência de más oclusões. Estomat Cult. 1970;4(1):35-42.

3. Almeida RR, Santos SCBN, Santos ECA, Insabralde CMB, Almeida MR. Mordida aberta anterior: considerações e apresentação de um caso clínico. Rev Dental Press Ortod Ortop Facial. 1998;3(2):17-29.

4. Almeida RR, Garib DG, Henriques JFC, Almeida MR, Almeida RR. Ortodontia preventiva e interceptora: mito ou realidade. Rev Dental Press Ortod Ortop Facial. 1999;4(6):97-108

5. Almeida RR, Almeida-Pedrin RR, Almeida MR, Garib DG, Almeida PCMR, Pinzan A. Prevalência das más oclusões: características hereditárias e congênitas, adquiridas, gerais, locais e proximais (hábitos bucais). Rev Dental Press Ortod Ortop Facial. 2000;5(6):107-29.

6. Angle EH. Classification of malocclusion. Dent Cosm. 1899;41(18):248-64.

7. Brandão AMM. Oclusão normal e má oclusão na dentição decídua: um estudo epidemiológico em pré-escolares do município de Belém-PA. Rev Paraense Odont. 1996;1(1):13-7.

8. Martins JCR, Sinimbú CMB, Dinelli TCS, Martins LPM, Raveli DB. Prevalência de má oclusão em pré-escolares de Araraquara: relação da dentição decídua com hábitos bucais e nível sócio-econômico. Rev Dental Press Ortod Ortop Facial. 1998;3(6):35-43.

9. Mathias RS. Prevalência de algumas anomalias de oclusão na dentição decídua: mordida cruzada posterior,apinhamento anterior, mordida aberta anterior e relação terminal dos segundos molares decíduos [dissertação]. São Paulo (SP): Universidade de São Paulo; 1984.

10. Moyers R. Ortodontia. $3^{\mathrm{a}}$ ed. Rio de Janeiro: GuanabaraKoogan; 1988.

11. Nyström M. Occlusal changes in the deciduous dentition of a series of Finnish children. Proc Finn Dent Soc. $1981 ; 77(5): 288-95$.
12. Organización Mundial de La Salud. Higiene dental: reseña de una reunión de un grupo de consultores. Cron OMS. 1955;9:11-6.

13. Proffit WR. Equilibrium theory revisited: factors influencing position of the teeth. Angle Orthod. 1978;48(3):175-86

14. Rebello Junior $W$, Toledo OA. A influência da fluoretação da água de consumo na prevalência das anormalidades de oclusão na dentição decídua de pré-escolares brancos da cidade de Araraquara. Rev Fac Farm Odontol Araraquara. 1975;9(1):9-15.

15. Silva Filho OG, Silva PRB, Rego MVNN, Silva FPL, Cavassan AO. Epidemiologia da má oclusão na dentadura decídua. Ortodontia. 2002;35(1):22-33.

16. Silva Filho OG, Cavassan AO, Rego MVNN, Silva PRB. Hábitos de sucção e má oclusão: epidemiologia na dentadura decídua. Rev Clín Ortod Dental Press. 2003;2(5):57-74

17. Silva Filho OG, Freitas SF, Cavassan AO. Prevalência de oclusão normal e má oclusão em escolares da cidade de Bauru (São Paulo). Parte I: relação sagital. Rev Odontol Uni São Paulo. 1990;4(2):130-7.

18. Silva Filho OG, Gonçalves RM, Maia FA. Sucking habits: clinical management in dentistry. J Clin Pediatr Dent. $1991 ; 15(3): 137-56$.

19. Strang RHA. A textbook of Orthodontics. Philadelphia: Lea \& Febiger; 1950.

20. Stratford NM. Malocclusion among Belfast school children. J Ir Dent Assoc. 1973;19(2):22-32.

21. Trottman A, Martinez NP, Elsbach HG. Occlusal disharmonies in the primary dentitions of black and white children. ASDC J Dent Child. 1999;66(5):332-6.

22. Tschill $P$, Bacon W, Sonko A. Malocclusion in the deciduous dentition of Caucasian children. Eur J Orthod. 1997;19(4):361-7.

23. Van Der Linden FPMG. Genetic and environmental factors in dentofacial morphology. Am J Orthod. 1966;52(8):576-83.

24. Wood AWS. Anterior and posterior crossbites J Dent Child. 1962;29(4):280-5.

Endereço para correspondência

Marcio Rodrigues de Almeida

Av. José Vicente Aielo, 7-70

CEP: 7053-011 - Bauru / SP

E-mail: marcioralmeida@uol.com.br 